\title{
Applications of Artificial Neural Network to Sheet Metal Work - A Review
}

\author{
Sachin Kashid, Shailendra Kumar
}

Dept. of Mechanical Engineering, S.V. National Institute of Technology, Surat, 395007, Gujarat, India

\begin{abstract}
Design of sheet metal components and press tools demands a high level of knowledge and industrial experience on the part of designers. Recently, various artificial intelligence (AI) techniques are being used in sheet metal work to reduce complexity; minimize the dependency on human expertise and time taken in design of parts and dies as well as to improve the design efficiency. Artificial neural network (ANN) technique is one of the most powerful tools for solving engineering design problems and minimizing errors in experimental data. This paper describes a comprehensive review of applications of ANN technique to sheet metal work. Major published research work in the domain area is summarized in tabular form. Based on the critical review of available literature, further research scope is identified. The present literature review reveals that there is stern need to apply ANN technique to press tool design and to predict tool life in sheet metal industries.
\end{abstract}

Keywords Artificial Intelligence (AI), Artificial Neural Network (ANN), Sheet metal work, Dies

\section{Introduction}

Sheet metal parts are important structural members of car bodies, aircrafts, beverage cans, home appliances, telecommunication equipments, and medical implants. Sheet metal processes are widely used in industries to manufacture these parts because its repeatability and high productivity[1]. Current market demands that sheet metal parts should be produced to precise shape or near precise shape with improved mechanical properties, smooth surface finish, good dimensional accuracy and material savings depending on service conditions[2-6]. Sheet metal manufacturer has to face a number of challenges like proper design of press tools (dies) to produce parts without any surface or internal defects, lower manufacturing cost, high productivity, minimum scrap and energy consumption [7-12]. Traditional methods of design of sheet metal parts and press tools are complex, laborious and highly dependent on human expertise. Some computer aided design (CAD), computer aided process planning (CAPP), computer aided engineering (CAE), and computer aided manufacturing (CAM) systems are used in sheet metal industries since last few decades to ease complexity and reduce time[13]. Although these systems provide assistance in design, drafting, analysis and manufacturing of sheet metal products, but domain experts are still required to take decisions at various stages of design and manufacturing.

During last 10-15 years, various artificial intelligence

* Corresponding author:

skbudhwar@med.svnit.ac.in (Shailendra Kumar)

Published online at http://journal.sapub.org/ajis

Copyright (C) 2012 Scientific \& Academic Publishing. All Rights Reserved
(AI) techniques have been applied for solving complicated problems in almost all areas of engineering. Recently, many researchers have also used artificial neural network (ANN) technique of AI for manufacturability analysis, process planning, die design, prediction of finite element simulation results etc. in sheet metal work[14]. Sheet metal product development and design of dies usually involve several design parameters. A subtle change of any parameter constitutes a new design scenario and new simulations are needed to explore its behaviours and performance. It is not practical to find the optimal solution through one-by-one simulation. To address this issue, ANN technique along with finite element method (FEM) can be used effectively for sheet metal product development and design of dies to find out the highly non-linear relationship between the designs parameters.

Artificial Neural Network (ANN) technique is the mimics of human brain. Neural network (NN) systems are combination of many simple processing elements which operate in parallel (also called parallel distributed function)[19]. ANN technique is capable to elevated functions, such as adaptation or learning, fault tolerance, input-output mapping, non-liner function and lower level functions such as data pre-processing for different kinds of inputs. NNs have been inspired both by human biological nervous systems and mathematical theories of learning, information processing and control as shown in Figure 1. ANN functions depend on the different kind of applications. Figure 1 shows $X_{1}, X_{2}, X_{3} \ldots X_{i}$ as the inputs with respect to $\mathrm{W}_{1}, \mathrm{~W}_{2}$ and $\mathrm{W}_{3} \ldots \mathrm{W}_{\mathrm{i}}$ as the weights of the input functions. All the input data (input function and weight function) are represented by linear combination of the output. 


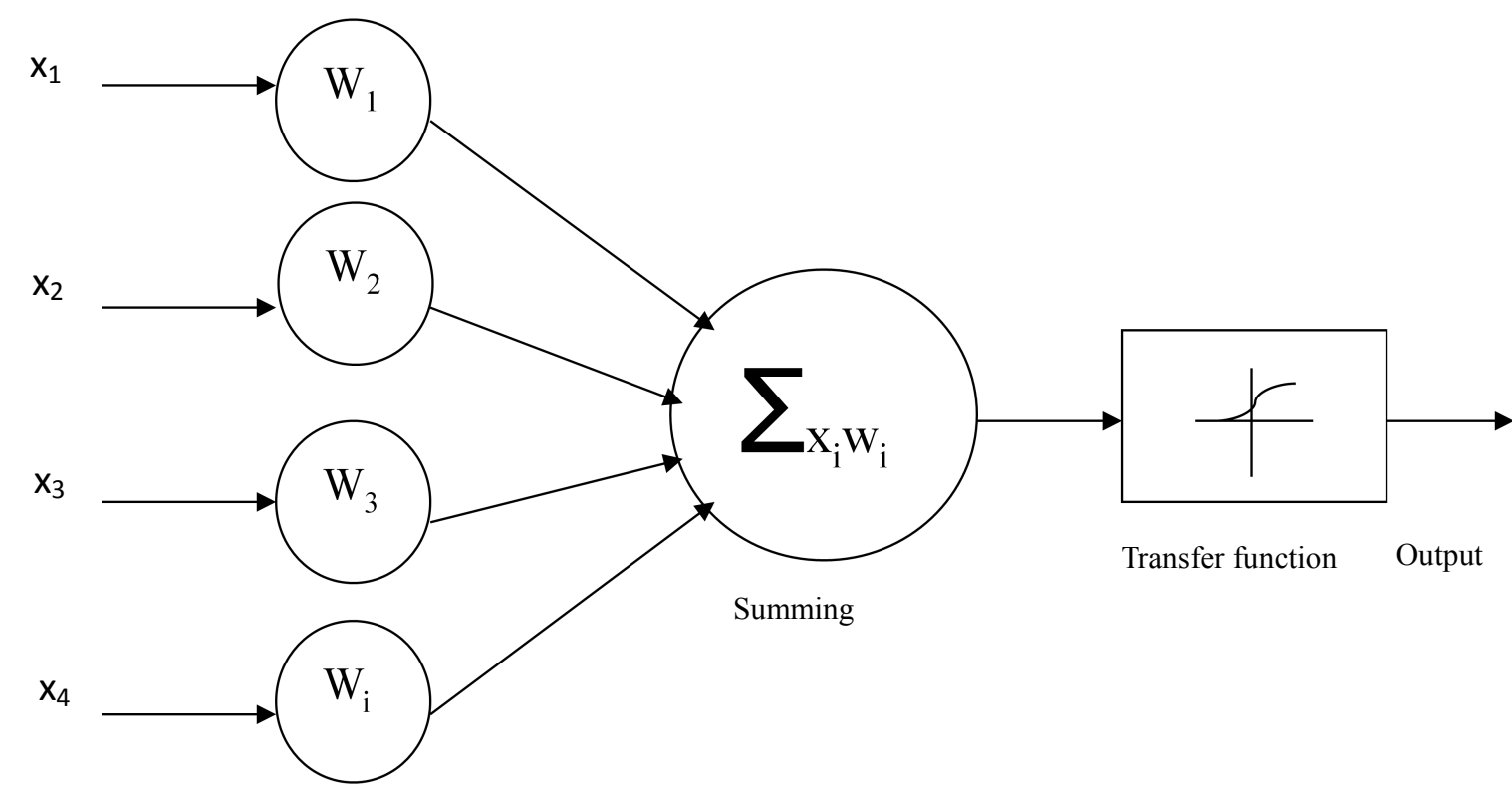

Figure 1. Artificial neural network

$$
\text { net }_{\mathrm{j}}=\sum \mathrm{X}_{\mathrm{i}} \mathrm{W}_{\mathrm{i}}
$$

i

Where, ' $\mathrm{j}$ ' is the communication link between neuron and computation neuron node is ' $i$ '. ANNs are nonlinear function processing structures in which the elements called as neurons process the information. Signals are transmitted from input to output which is called connecting links. The connecting links are associated to weight, which is multiplied along with the incoming signal i.e. net input for any typical neural network. The output signal is obtained by applying activations to the net input. An ANN is configured for a specific application, such as pattern recognition or data classification, through a learning process. Learning in biological systems involves adjustments to the synaptic connections that exist between the neurons.

In the present work, available published literature in the area of applications of ANN technique to sheet metal work is reviewed. Salient features of some important systems developed by worldwide researchers are presented in tabular form and then finally, the scope of further work in the domain of sheet metal is identified.

\section{Review of ANN Applications to Sheet Metal Work}

Traditionally sheet metal work is tedious, complex, time consuming, and experienced based process. Applications of ANN technique to sheet metal work have given a new dimension in the late 1990 and early 1995s. ANN technique to sheet metal involves process planning; die design, prediction of FEM results etc. These are important activities of sheet metal product development. Process planning determines the values of various process parameters, detail of operations, strip layout design etc. During the process of die design, designer has to determine the type and size of various die components, their modelling and material selection. Worldwide researchers used ANN technique for development of various systems to ease the activities related to sheet metal work.

Lin and Chang[13] proposed NN based expert system of sheet metal bending tooling. According to training and testing of networks, the knowledge acquisition and knowledge inference in the expert system are used. They divided learning model into two categories according to their problem attributes; digital attributes and conditional attributes. Conditional attributes is used as a learning model. Roy[14] demonstrated sheet metal bending with the help of ANN. ANN is used to predict the forces required for a number of bending experiments and to achieve a zero spring-back angle. They used multilayer perceptron neural networks with back propagation learning algorithm. Hyperbolic tangent is used as activation function. Lin and Chang[15] introduced fuzzy set theory, ANN and expert system to the design details of the uncertainty portion of progressive die design. For design of progressive die, various parameters are considered such as die block thickness, die clearance angle, die sets, stripping pressure, die with guide bushing etc. Back propagation algorithm is used for training. Ruffini and Cao[16] proposed ANN and FEM to minimize spring-back in a cannel forming process. From FEM point of view they considered several factors such as material properties, sheet thickness, lubrication conditions, tooling geometry and processing parameters. Multilayer feed forward NN with back propagation algorithm is used. Manfred Geiger et al.[17] developed ANN for cost estimation of large scale production of sheet metal parts. For the input layer of ANN they considered number of strokes, number of tool stages, number of border elements and stampings. For the learning purpose quick prop algorithm is used. Manabe et al.[18] proposed combination of ANN and 
the elementary plasticity theory for identification of material properties and lubrication condition in the deep-drawing process. They considered input data such as punch load, punch stroke, blank holding force, flange thickness strain, flange reduction ratio etc., and the output data of ANN as plastic anisotropic coefficient, plastic coefficient, and work-hardening exponent etc. Back propagation algorithm is used. Forcellese et al.[19] applied ANN to air bending process. They considered input pattern of ANN as bend angle after unloading, sheet thickness, mechanical behaviour of the material, bending force and punch, displacement and the output pattern of ANN is punch stroke. They used back propagation algorithm and bipolar sigmoid activation function. Wu et al.[20] presented combination of ANN and machine learning methods for surface defect (wrinkling and buckling) investigation in sheet metal forming. They considered six variables (geometrical features) for surface defect like height gradient, boundary of torsion gradient, torsion went, boundary of curvature gradient, boundary of height gradient, curvature gradient etc. Logistic, linear threshold or hard limiting (on/off) as activation function and feed-forward back propagation $\mathrm{NN}$ is used. Wadi and Balendra[21] proposed ANN model for prediction of blanking process and blanking parameters by analyzing acoustic emission (AE) and force/displacement waves. They used AE sensors, digital signal processing (DSP) hardware and acquisition software for measure $\mathrm{AE}$ signals and force/displacement signals. They considered number of ANN input parameters such as die-edge profile, the punch-edge profile and the punch-die from $\mathrm{AE}$ waves and force/displacement signals. Back propagation algorithm is used. They used specialized software called NeuroShell2 for the ANN models and to test them. Ivezic et al.[22] applied ANN to inverse modelling of material deformation. They used gradient descent and back propagation algorithm.

Kim and Kim[23] proposed ANN and FEM for metal forming process. ANN is used to reduce the number of finite element simulation for designing die of forging products. Three-layer $\mathrm{NN}$ and back propagation algorithm is used to train. Inamdar et al.[24] developed ANN system for prediction of spring back in air vee bending of metallic sheets. Back propagation algorithm is used. They considered five inputs (angle of bend, punch radius/thickness ratio, die gap, die entry radius, yield strength to Young's modulus ratio and the strain hardening exponent), ten hidden and two output nodes (punch displacement and springback angle). Multi-layer perceptron (MLP) NN is developed and used for the prediction of spring-back. Further they[25] developed ANN technique for prediction of spring-back in air vee bending. They considered two-layers with a sigmoid activation function as well 5 input nodes, 10 hidden nodes and 2 output nodes. Further they developed ANN codes. Different types of functions are used for validation of code like trigonometric, exponential, and logarithmic. Back propagation algorithm with momentum in the batch mode of learning is used. Cheng and Lin[26] used ANN to predict bending angle of sheet metal formed by laser. They considered several $\mathrm{NN}$ input parameters such as spot diameter, scan speed, laser power, and work piece geometries including thickness and length of sheet metal work piece. They used three supervised neural networks to estimate bending angles formed by a laser. Drugos et al.[27] applied NN technique for prediction of laser sheet metal bending. They considered input parameters such as thickness of materials, laser power beam and scanning speed. They used back propagation algorithm for learning and multi-layer perceptron. Further they used non-linear sigmoid function as an activation function. Wang et al.[28] introduced ANN to predict and avoid surface failures, such as wrinkling in sheet metal forming. They considered three input data of ANN model such as curvature, torsion, and height (vertical displacement of each point from its initial position). Supervised back propagation algorithm is used for training purpose. Hambli[29] used combination of ANN and FEM for prediction of burr height formation in blanking process. They used back propagation algorithm for training purpose and predicted burr height of blanked parts versus tool wear state and punch-die clearance. Further they used multi-layer perceptrons (MLP) architecture and sigmoid (logistic) as an activation function. Frayman et al.[30] developed ANN for inverse model of a sheet forming process, and compare its performance with that of a linear model. They considered input parameters such as blank holder force, die radius and tool gap. They used linear regression model, feed forward MLP model and compared these result with each other. Further they used back propagation algorithm for training and hyperbolic tangent is used as an activation function. Luo et al.[31] developed ANN and analytic method to overcome the defects in deep drawing process. Three layer back propagation algorithm is used for learning purpose and for identification of material properties. Flange thickness strain, flange reduction ratio, drawing force, drawing height and blank holder force are taken as inputs of ANN model. Hambli and Guerin[32] used ANN for prediction of optimum punch-die clearance in sheet metal blanking process with the help of FEM methods. They used back propagation algorithm for training purpose, multi-layer perceptrons (MLP) architecture and sigmoid (logistic) as an activation function. Slomp and Klingenberg[33] proposed ANN for detection of punching/blanking characteristics from the Force-Displacement graph. Hsiang and $\mathrm{Ho}[34]$ investigated FEM and ANN methods to plan the radial forging of work-hardened materials to yield the optimal designed die. For the FEM analysis of radial forging process, they considered number of parameters like die corner radius, ring gap height, friction factor, work hardening coefficient, gap between the billet and die and the punch load etc. The multilayer perceptron $\mathrm{NN}$ and back propagation algorithm are used.

Hambli[35] proposed FEM and ANN methods to predict the optimum punch-die clearance during sheet metal blanking processes. In FEM analysis a number of parameters like blanking clearance, wear state of tool, and thickness of sheet etc. are considered. ANN technique is used for 
mapping between inputs to output data (FEM simulation data). Three-layered feed-forward $\mathrm{NN}$ with one neuron in the input layer, 15 in the hidden layer, and one in the output layer are used. Back propagation algorithm is used for training purpose. Pathak et al.[36] studied prediction responses of the sheet metal bending process using ANN. Forty four cases are analyzed using FEM to train NN. They considered input data of ANN as sheet thickness, die radius, effective stress and residual stress and the output of ANN as spring-back, plastic strain, residual plastic strain, and load. They used back propagation algorithm for trained input and output data of ANN. Zhao and Wang[37] presented a feed-forward NN model based on the LM algorithm (put forward by Levenberg and Marquardt) to realize real-time identification of material properties and friction coefficient for deep drawing of an axisymmetric work piece. Singh and Kumar[38] used ANN to predict the thickness along a cup wall in hydro-mechanical deep drawing. After using the experimental results to train and test the network, the model was applied to new data for the prediction of thickness strains in hydro-mechanical deep drawing. FE simulation of the process for the two-dimensional axisymmetric case was also performed using explicit FE code LS-DYNA 2D. The inputs of the model were material and process parameters and the output was thickness strains along the cup wall. They used feed-forward back prorogation NN.

Liu et al.[39] proposed a technique based on ANN and genetic algorithm (GA) to solve the problem of spring-back in sheet metal forming. They investigated spring-back of the typical U-shaped bending. Based on production experiment, the prediction model of spring-back was developed by NN and GA. Further study on the relation of spring-back and various process parameters is also carried out on the model of spring-back. They used back propagation algorithm. Pathak et al.[40] used ANN for prediction of geometrical instabilities like wrinkling and necking in deep drawing. They considered number of parameters like die radius, punch radius, blank radius, punch corner radius, die corner radius, drawing ratio, blank thickness, and stroke length for $\mathrm{FE}$ analysis. Further they considered strength coefficient, strain hardening exponent, friction coefficients for training of the network. 2-6-3 size of back propagation algorithm is used for modelling. Verlinden et al.[41] developed ANN system for cost estimation of sheet metal parts. They mainly considered geometrical aspects for the cost estimation; all necessary data comes from the CAD file of the part or from a simple sketch. They used regression analysis and to test ANN in MATLAB. Levenberg-Marquardt (LM) algorithm is used for training. Klingenberg and Boer[42] presented a review and proposal for condition-based maintenance $(\mathrm{CBM})$ in blanking of sheet metal. Previous statistical, AI and model based approaches are analyzed. Further they demonstrated how the signature of the force-displacement relation changes significantly with increasing tool wear in a typical configuration of sheet steel blanking. Bozdemir and Golcu[43] used ANN to determine the effects of material, bending angle and ratio of bend angle to sheet thickness on spring-back angle. Training of the network is performed using Levenberg-Marquardt (LM), Scaled Conjugate Gradient (SCG), and Polo-Ribiere Conjugate Gradient (CGP) back propagation algorithms. Ruan et al.[44] used back propagation, NN and GA to predict spring-back of complex sheet metal forming parts. GA is used for optimization of the weights of back propagation neural network and the results are compared with those of traditional BP neural network and regression model. Kurtaran[45] compared experimental (data table approach), empirical, ANN and Response Surface (RS) approaches for bend allowance calculation in air bending. It is concluded that ANN model is computationally costly in training phase, but once it is trained it can be effectively used. Back propagation algorithm for training and MATLAB tool box is used for programming. Sivasankaran et al.[46] developed ANN model for predicting and avoiding surface failure such as wrinkling of sheet metals. ANN model is proposed to map the mechanical properties (diameter of cup, thickness of cup wall, radial strain, and hoop strain) and instantaneous geometry features of deep drawing process. They used feed forward back propagation $\mathrm{NN}$ algorithm and it is trained and tested with pairs of inputs/outputs data. Kazan et al.[47] developed prediction model of spring-back in wipe-bending process of sheet metal using ANN approach. Several numerical simulations using FEM were performed to obtain the teaching data of NN. Aguir et al.[48] presented an inverse strategy coupled with an ANN model for identification of anisotropic parameters of cylindrical cup deep drawing. ANN model is trained by finite element simulations. They considered several input parameters for FE simulation such as draw ratio, clearance between punch and die, punch and die corner radii, sheet initial thickness, blank holder force, friction at punch-die-work piece interface and punch speed. Further they used multilayer perception trained by back propagation. Also sigmoid function is used as an activation function.

Djavanroodi et al.[49] investigated the possibility of using FEM together with ANN for the analysis of fine blanking process. Three hidden layer with Levenberg-Marquardt (LM) algorithm is used. They concluded that a combination of FEM and ANN helps to reduce the simulation time and make it possible to search for the optimal process parameters in fine-blanking. Li et al.[50] used ANN and GA for optimization of sheet metal deep drawing with variable blank holder force. The experimental work is performed on automobile headlight reflector. Hanazono et al.[51] reported to use ANN to determine parameters of slide-bending formation of metallic sheet. Hierarchical NN is used for slide-bending formation. The inputs of the network are sheet thickness, bending angle and curvature radius and the outputs are vertical load and sliding distance. The relation of inputs and outputs is trained using error back propagation. One hidden layer is used and the number of neurons of the hidden layers is five. Fu et al.[52] developed three-layer back propagation $\mathrm{NN}$ to predict punch radius based on the results of air-bending experiments of sheet metal. GA is used to 
optimize the weights of $\mathrm{NN}$ for minimizing the error between the predictive punch radius and the experimental one. Liu and Yi[53] used combination method of test design, FEM and NN modeling for prediction of spring-back of automobile ceiling. They considered six parameters such as plate thickness die gap, friction coefficient, die fillet, stamping velocity and blank holder force. Average spring back values are calculated by FEM simulation and modeling samples are obtained from orthogonal test design. Further they used three NN models (Back Propagation, Radial Basis Function, and Generalized Regression) for prediction of spring-back. Deng and Zhang[54] tried to build a function relationship between the spring-back and the craft parameters with ANN. They introduced GA to solve the problem of base function centers distribution. Further they applied GRNN (genetic algorithm and radical base function neural network) for predicting the spring-back accurately. Gugel and Schrödl[55] used ANN for the cost forecasting of sheet metal parts. To define the topology of ANN, systematic variations of the number of hidden layers and the numbers of neurons per hidden layer are applied. Standard back propagation is used as training method. Du et al.[56] proposed Double Chains Quantum Genetic Algorithm (DCQGA) and back propagation $\mathrm{NN}$ for prediction of bending angle in the laser bending process of sheet metal. Tansig function is used as an activation function and Levenberg-Marquardt algorithm is used to train the network. Gisario et al.[57] investigated spring-back control in the bending process of aluminum sheets by hybrid forming process. They proposed NN solutions to improve the matching between experimental and numerical data, with the Multi-Layer Perceptrons (MLPs) trained by back propagation algorithm. Baseri et al.-[58] proposed new fuzzy learning algorithm of back propagation $\mathrm{NN}$ to predict the spring-back in the V-die bending process. The significant input parameters are considered to determine the effect of the parameters on the bend angle. The required training and validation data are obtained from experimental observation. They used fuzzy learning back-propagation (FLBP) algorithm, constant learning rate back-propagation (CLBP) and the variable learning rate back-propagation (VLBP) algorithms. Log-sigmoid function is used as an activation function. Ren et al.[59] used back propagation $\mathrm{NN}$ to establish the intelligent prediction model of pipe forming process parameters, and the main process parameters including bending moment. Zhang[60] used FEM simulation and ANN to optimize the blank holder force (BHF) for drawing of automobile fuel tank. They established radial basis function (RBF) NN model to simulate the nonlinear mapping relation between BHF and sheet forming parameters. Singh et al.[61] applied error back propagation $\mathrm{NN}$ in collaboration with GA to investigate the role of die radius, punch radius, friction coefficients and drawing ratios for axisymmetric deep drawing process. Choi et al.[62] proposed a channel-type indirect blank holder to develop a high-strength center pillar in form-type hot stamping, so that severe wrinkling at the flange can be reduced. Slope angle and corner radius of the channel are selected as the main shape parameters by FE analysis and ANN. Nasrollahi and Arezoo[63] investigated the influence of process variables such as hole type, number of holes, the ratio of hole width to sheet width, die radius and pad force on spring-back in sheet metal components using FEM and ANN.

The reviewed literature in the area of applications of ANN to sheet metal is summarized in table 1 .

Table 1. Summary of reviewed literature

\begin{tabular}{|c|c|c|c|}
\hline Ref. No. & Researchers & System Details & Remark \\
\hline 13 & Lin and Chang[1995] & $\begin{array}{l}\text { Used NN for development of expert system. } \\
\text { BP algorithm is used }\end{array}$ & High errors on results \\
\hline 14 & $\operatorname{Roy}[1996]$ & $\begin{array}{l}\text { Used Multi-layer perceptron (MLP) NNs with BP learning } \\
\text { algorithm and hyperbolic tangent for activation function }\end{array}$ & Requires high processing time \\
\hline 15 & Lin and Chang[1996] & Used BP NN & $\begin{array}{l}\text { Developed for specific application like } \\
\text { progressive die }\end{array}$ \\
\hline 16 & Ruffini and Cao[1998] & $\begin{array}{l}\text { Used feed forward neural network with back propagation } \\
\text { algorithm }\end{array}$ & Requires trained person to operate \\
\hline 17 & Geiger et al.[1998] & Used quickprop algorithm for learning & Specific application like progressive die \\
\hline 18 & Manabe et al.[1998] & Used back propagation algorithm & Requires trained person to operate \\
\hline 19 & $\begin{array}{l}\text { Forcellese et al. } \\
\quad[1998]\end{array}$ & $\begin{array}{l}\text { Used back propagation algorithm and bipolar sigmoid activation } \\
\text { function }\end{array}$ & Requires trained person to operate \\
\hline 20 & Wu et al.[1999] & $\begin{array}{l}\text { Used logistic, linear threshold or hard limiting (on/off) as } \\
\text { activation function }\end{array}$ & System takes more time \\
\hline 21 & $\begin{array}{c}\text { Wadi and } \\
\text { Balendra[1999] }\end{array}$ & Used BP algorithm & Requires trained person \\
\hline 22 & Ivezic et al.[1999] & Used gradient descent and BP algorithm & System is very slow \\
\hline 23 & Kim and $\operatorname{Kim}[2000]$ & Used three layer NN and BP algorithm for training & Requires experienced person \\
\hline 24 & Inamdar et al.[2000] & Used BP algorithm and MLP NN & Requires experienced person \\
\hline 25 & Inamdar et al.[2000] & Used BP algorithm and two-layer with a sigmoid activation & Difficult coding \\
\hline
\end{tabular}




\begin{tabular}{|c|c|c|c|}
\hline & & function & \\
\hline 26 & Cheng and $\operatorname{Lin}[2000]$ & $\begin{array}{c}\text { Used BPHTF(Hyperbolic Tangent Function), BPLF(Logistic } \\
\text { Function), RBFN (Radial Basis Function NN) }\end{array}$ & System takes more time to simulate \\
\hline 27 & Drugos et al.[2000] & Used BP algorithm for learning and MLP NN & Considered partial material properties \\
\hline 28 & Wang et al.[2000] & Used supervised BP algorithm & Requires expert person \\
\hline 29 & Hambli[2002] & $\begin{array}{l}\text { Used BP algorithm, MLP and sigmoid (logistic) as an } \\
\text { activation function }\end{array}$ & $\begin{array}{c}\text { Limited for specific problem like burr } \\
\text { height }\end{array}$ \\
\hline 30 & Frayman et al .[2002] & Used linear regression model and feed forward MLP model & Requires more input data \\
\hline 31 & Luo et al.[2003] & Used three layer BP algorithm & Semi-automatic approach \\
\hline 32 & $\begin{array}{l}\text { Hambli and Guerin } \\
\text { [2003] }\end{array}$ & Used three layer feed forward NN and MLP & $\begin{array}{l}\text { Developed for specific application like } \\
\text { sheet metal blanking }\end{array}$ \\
\hline 33 & $\begin{array}{c}\text { Slomp and } \\
\text { Klingenberg[2004] }\end{array}$ & $\begin{array}{l}\text { Used pattern recognition for monitoring and diagnosis of } \\
\text { punching/blanking process }\end{array}$ & Recognition takes more time \\
\hline 34 & Hsiang and $\mathrm{Ho}[2004]$ & Used MLP and BP algorithm & Requires huge input data \\
\hline 35 & Hambli[2005] & Used Three-layered feed-forward NN with BP algorithm & Requires experienced person \\
\hline 36 & Pathak et al.[2005] & Used sigmoid function and BP algorithm & Trained person is required to operate \\
\hline 37 & Zhao and Wang[2005] & Used feed-forward NN model based on the LM algorithm & System is complicated to understand \\
\hline 38 & $\begin{array}{l}\text { Singh and } \\
\text { Kumar[2005] }\end{array}$ & Used BP algorithm in order to train gradient descent & $\begin{array}{l}\text { LS-DYNA 2D software is rarely used in } \\
\text { stamping industries }\end{array}$ \\
\hline 39 & Liu et al.[2007] & Used GA-ANN techniques. Also BP algorithm is used & Requires trained person \\
\hline 40 & Pathak et al.[2008] & Used 2-6-3 size of BP algorithm & Simulation takes more time \\
\hline 41 & Verlinden et al.[2008] & Used Levenberg-Marquardt (LM) algorithm & Developed for specific application \\
\hline 42 & $\begin{array}{l}\text { Klingenberg and } \\
\text { Boer[2008] }\end{array}$ & $\begin{array}{l}\text { Used ANN, expert system and UML-based diagramming } \\
\text { technique }\end{array}$ & $\begin{array}{l}\text { Very limited application like } \\
\text { condition-based maintenance in } \\
\text { punching/blanking of sheet metal }\end{array}$ \\
\hline 43 & $\begin{array}{l}\text { Bozdemir and } \\
\text { Golcu[2008] }\end{array}$ & $\begin{array}{l}\text { Used LM, scaled conjugate gradient (SCG), Polo-Ribiere } \\
\text { conjugate gradient (CGP) BP algorithm for training }\end{array}$ & Requires highly skilled person to operate \\
\hline 44 & Feng et al.[2008] & Used BP NN, GA and regression model & Requires huge input data \\
\hline 45 & Kurtaran[2008] & Used BP algorithm and Sigmoid (logistic) function & Frequently uses Response Surface models \\
\hline 46 & $\begin{array}{l}\text { Sivasankaran et } \\
\text { al.[2009] }\end{array}$ & Used feed forward NN and BP algorithm & Simulation takes more time \\
\hline 47 & Kazan et al.[2009] & Used BP algorithm & Need expert person \\
\hline 48 & Aguir et al.[2009] & Used MLP trained by back propagation & $\begin{array}{l}\text { Developed for specific application like } \\
\text { cylindrical cup drawing }\end{array}$ \\
\hline 49 & $\begin{array}{l}\text { Djavanroodi et } \\
\text { al.[2010] }\end{array}$ & Used LM with three hidden layer & Requires experienced person \\
\hline 50 & Li et al.[2010] & Used ANN and GA & Computation takes more time \\
\hline 51 & Masaki[2010] & Used error BP algorithm & $\begin{array}{l}\text { Limited application like slide bending } \\
\text { formation of metallic sheet }\end{array}$ \\
\hline 52 & Fu et al.[2010] & Used three-layer BP NN & Requires experienced person \\
\hline 53 & Liu and Yi[2010] & $\begin{array}{c}\text { Used BP NN, Radial Basis Function NN and Generalized } \\
\text { Regression NN }\end{array}$ & Limited application like automobile ceiling \\
\hline 54 & Deng and Zhang[2010] & $\begin{array}{l}\text { Used GRNN (genetic algorithm and radical base function neural } \\
\text { network) }\end{array}$ & Requires huge input data \\
\hline 55 & $\begin{array}{c}\text { Gugel and } \\
\text { Schrödl[2010] }\end{array}$ & Used BP algorithm and logistic function & Limited application \\
\hline 56 & Du et al.[2010] & Used LM algorithm & Requires experienced person \\
\hline 57 & Gisario et al.[2011] & $\begin{array}{l}\text { Used MLPs with BP algorithm and generalized feed-forward } \\
\text { multi-later perceptrons (GFF-MLPs) }\end{array}$ & Difficult to operate \\
\hline 58 & $\begin{array}{l}\text { Baseri et al. } \\
\text { [2011] }\end{array}$ & Used fuzzy learning BP algorithm FLBP, CLBP and VLBP & $\begin{array}{l}\text { FLBP, CLBP and VLBP are rarely used in } \\
\text { stamping industries }\end{array}$ \\
\hline 59 & Ren et al.[2011] & Used BP algorithm and tansig transfer function & Requires expert person \\
\hline 60 & Zhang[2011] & Used radial basis function (RBF) NN model & $\begin{array}{l}\text { Requires experienced person and FEM } \\
\text { simulation takes more time }\end{array}$ \\
\hline 61 & Singh et al.[2011] & Used error BP NN and GA & Developed for specific application like deep \\
\hline
\end{tabular}




\begin{tabular}{|c|c|c|c|}
\hline & & & drawing \\
\hline 62 & Choi et al.[2011] & Used root-mean-square (RMS) & Limited application \\
\hline 63 & $\begin{array}{c}\text { Nasrollahi and } \\
\text { Arezoo[2012] }\end{array}$ & Used MLP, BP NNs with LM training function & $\begin{array}{c}\text { Developed for specific application like } \\
\text { spring-back with holes on bending area }\end{array}$ \\
\hline
\end{tabular}

\subsection{Comments on Reviewed Literature}

The review of available literature in the area of applications of ANN to sheet metal work reveals that this technique is used by worldwide researchers for specific applications like process control, process planning, quality control, prediction of bending, feature recognition, tool design, and cutting tool selection etc. But for most of these applications, experienced persons are required to operate the developed system and to take suitable decisions at various stages of sheet metal work. In sheet metal industries, still it is believed that the success of the defect free production of sheet metal parts largely depends upon the skill and the experience of the product designer. It seems that there is lack of explanation (theoretical) facilities in the developed ANN applications to sheet metal work. Further, literature is also not available on the applications of ANN to the design of multi-operation press tools such as progressive die, combination die and compound die, which are widely used in sheet metal industries.

\section{Conclusions}

Published literature in the area of applications of ANN to sheet metal work is reviewed and summarized in tabular form. Most of the available research work deals with the prediction of sheet metal bending processes. No research work is reported related to the application of ANN technique to design of sheet metal dies (such as blanking die, compound die, progressive die, combination die) and prediction of die life to assist designers working in sheet metal industries. Therefore, there is stern need to apply ANN technique in these identified areas. The developed ANN system for product design and die design must be user friendly, easy to operate and have low cost of implementation.

\section{REFERENCES}

[1] V. Naranje and S. Kumar, "AI Applications to Metal Stamping Die Design - A Review", World Academy of Science, Engineering and Technology, vol. 68, pp.1516-1522, 2010.

[2] H.S. Ismail, K. K. B. Hon and K. Huang, "An intelligent object-oriented approach to the design and assembly of press tools," Ann. CIRP, vol.44, pp. 91-96, 1995.

[3] S. Kumar and R. Singh, "A low cost knowledge base system framework for progressive die design", Journal of Materials Processing Technology, vol. 153-154, pp. 958-964, 2004.
[4] S. Kumar and R Singh, "An automated design system for progressive die", Expert Systems with Applications, vol.38 pp.4482-4489, 2011.

[5] I. Toktas and A.T. Özdemir, "Artificial neural networks solution to display residual hoop stress field encircling a split-sleeve cold expanded aircraft fastener hole", Expert Systems with Applications, vol.38 pp.553-563, 2011.

[6] M. Sedighi, M. Hadi and S. Kolahdouz, "Optimization of Preform in Close Die Forging by Combination Of Neural Network and Genetic Algorithm", World Applied Sciences Journal, vol. 7 (11) pp.1464-1473, 2009.

[7] R. Hambli, "Statistical damage analysis of extrusion processes using finite element method and neural networks simulation", Finite Elements in Analysis and Design, vol.45 pp.640-649, 2009.

[8] V. B. Rao and H.V. Rao, "C++ Neural Networks and Fuzzy Logic”, MIS:Press, USA, 1993.

[9] W. Zhang, "Design for uncertainties of sheet metal forming process", Ph.D. thesis report, 2007.

[10] Y. Yu, W. Min, W. Haibo and H. Lin, "Design and Optimization of Press Bend Forming Path for Producing Aircraft Integral Panels with Compound Curvatures", Chinese Journal of Aeronautics, vol. 23, pp.274-282, 2010.

[11] H. Yan and J. Xia, "An approach to the optimal design of technological parameters in the profile extrusion process", Science and Technology of Advanced Materials, vol.7, pp. 127-131, 2006.

[12] P. N. Oba, "Quality analysis modeling for development of a process controller in resistance spot welding using neural network techniques", Ph.D. thesis, 2006.

[13] Z. C. Lin and D. Y. Chang, "Application of a neural network machine learning model in the selection system of sheet metal bending tooling", Artificial intelligence in engineering, vol.10, pp.21-37, 1995.

[14] R. Roy, "Assessment of Sheet-Metal Bending Requirements Using Neural Networks", Neural Computing \& Applications, vol. 4 pp.35-43, 1996.

[15] Z. C. Lin and H. Chang, "Application of fuzzy set theory and back propagation neural networks in progressive die design", Journal of manufacturing system, Vol.15 (4), pp.268-281, 1996.

[16] R. Ruffini and J. Cao, "Using Neural Network for Springback Minimization in a Channel Forming Process", Journal of Materials \& Manufacturing, vol.107, Section 5, pp.65-73, 1998.

[17] M. Geiger, J. Knoblach and F. Backes, "Cost Estimation for Large Scale Production of Sheet Metal Parts Using Artificial Neural Networks", University of Erlangen-Nuremberg, Institute for Manufacturing Science, production engineering, vol. v/2, pp.81-84, 1998. 
[18] K. Manabe, M. Yang and S. Yoshihara, "Artificial intelligence identification of process parameters and adaptive control system for deep-drawing process", Journal of materials processing technology, vol.80-81 pp.421-426, 1998.

[19] A. Forcellese, F. Gabrielli and R. Ruffini, "Effect of the training set size on springback control by neural network in an air bending process", Journal of Materials Processing Technology, vol. 80-81 pp.493-500, 1998.

[20] X. Wu, J. Wang, A. Flitman and P. Thomson, Neural and Machine Learning to the Surface Defect Investigation in Sheet Metal Forming, 6th International Conference on Neural Information Processing Proceedings, Perth AUSTRALIA, November 16-20, 1999, IEEE, Inc., New Jersey USA, pp. 1088-1093, 1999.

[21] I. Wadi and R. Balendra, "Using neural networks to model the blanking process", Journal of Materials Processing Technology, vol. 91, pp.52-65, 1999.

[22] N. Ivezic, J. D. Allen Jr., and T. Zacharia, Neural Network Method for in Modeling of Material Deformation, Proc. Second Int. Conf. on Intelligent Processing and Manufacturing of Materials IPPM'99, pp.961-966, 1999.

[23] D. J. Kim and B. M. Kim, "Application of neural network and FEM for metal forming processes", International Journal of Machine Tools \& Manufacture, vol. 40, pp.911-925, 2000.

[24] M. V. Inamdar, P. P. Date, and U. B. Desai, "Studies on the prediction of springback in air vee bending of metallic sheets using an artificial neural network", Journal of Materials Processing Technology, vol. 108, pp.45-54, 2000.

[25] M. V. Inamdar, P. P. Date, K. Narasimhan, S.K. Maiti, and U.P. Singh, "Development of an Artificial Neural Network to Predict Springb ack in Air Vee Bending", Int J Advanced Manufacturing Technology, Vol. 16, pp. 376-381, 2000.

[26] P. J. Cheng and S. C. Lin, "Using neural networks to predict bending angle of sheet metal formed by laser", International Journal of Machine Tools \& Manufacture, vol. 40 pp.1185 $-1197,2000$.

[27] V. Drugos, V. Dun and R. Kovucevic, "Prediction of the laser sheet bending using neural network", IEEE International Symposium on Circuits and Systems, Geneva, pp.686-689, 2000.

[28] J. Wang, X. Wu, P. F. Thomson and A. Flitman, “A neural networks approach to investigating the geometrical influence on wrinkling in sheet metal forming", Journal of Materials Processing Technology, vol.105, pp.215-220, 2000.

[29] R. Hambli, "Prediction of burr height formation in blanking processes using neural network", International Journal of Mechanical Sciences, vol.44, pp. 2089-2102, 2002.

[30] Y. Frayman, B. F. Rolfe and G. I. Webb, "Improving an Inverse Model of Sheet Metal Forming by Neural Network Based Regression", The 2002 ASME Computers and Information in Engineering Conference, pp.1-8, 2002.

[31] Y. J. Luo, Y. Q. Zhang and D. N. He, "Determination of blank holder force in sheet metal deep drawing process", ACTA metallurgica sinica (English letters), Vol.16 (1), pp. 31-34, 2003.

[32] R. Hambli and F. Guerin, "Application of a neural network for optimum clearance prediction in sheet metal blanking processes", Finite Elements in Analysis and Design, vol.39, pp.1039-1052, 2003.

[33] J. Slomp and W. Klingenberg, "A Proposal to Use Artificial Neural Networks for Process Control of Punching/Blanking Operations", Flexible Automation and Intelligent Manufacturing, FAIM2004 Toronto, Canada, pp.556-562, 2004.

[34] S. H. Hsiang and H. L. Ho, "Application of finite element method and artificial neural network to the die design of radial forging processes", Internation Journal of Advanced Manufacturing Technology, vol. 24, pp.700-707, 2004.

[35] R. Hambli, Optimization of Blanking Processes Using Neural Network Simulation", The Arabian Journal for Science and Engineering, vol. 30, pp.3-16, 2005

[36] K. K. Pathak, S. Panthi, and N. Ramakrishnan, "Application of Neural Network in Sheet Metal Bending Process", Defence Science Journal, vol. 55, pp. 125-131, 2005.

[37] J. Zhao and F. Wang, "Parameter identification by neural network for intelligent deep drawing of axisymmetric workpiece", Journal of Materials Processing Technology, vol. 166, pp.387-391, 2005.

[38] S. K. Singh and D. R. Kumar, "Application of a neural network to predict thickness strains and finite element simulation of hydro-mechanical deep drawing”, International Journal of Advanced Manufacturing Technology, vol.25, pp.101-107, 2005.

[39] W. Liu, Q. Liu, F. Ruana, Z. Liang and H. Qiu, "Springback prediction for sheet metal forming based on GA-ANN technology", Journal of Materials Processing Technology, vol.187-188, pp.227-231, 2007.

[40] K. K. Pathak, V. K. Anand and G. Agnihotri, "Prediction of Geometrical Instabilities in Deep Drawing in Artificial Neural Network", Journal of Engineering and Applied Sciences, vol. 3(4), pp.344-349, 2008.

[41] B. Verlinden, J. R. Duflou, P. Collin and D. Cattrysse, "Cost estimation for sheet metal parts using multiple regression and artificial neural networks: A case study", International Journal of Production Economics, vol.111, pp.484-492, 2008.

[42] W. Klingenberg and T. W. Boer, "Condition-based maintenance in punching/blanking of sheet metal", International Journal of Machine Tools \& Manufacture, vol. 48, pp.589-598, 2008.

[43] M. Bozdemir and M. Golcu, "Artificial neural network analysis of springback in $\mathrm{V}$ bending", journal of applied science, vol. 8 (17), pp.3038-3043, 2008.

[44] F. Ruan, Y. Feng and W. Liu, "Springback Prediction for Complex Sheet Metal Forming Parts Based on Genetic Neural Network", IEEE, vol.1 pp.157-161, 2008.

[45] H. Kurtaran, "A novel approach for the prediction of bend allowance in air bending and comparison with other methods", International Journal of Advanced Manufacturing Technology, vol.37, pp.486-495, 2008.

[46] S. Sivasankaran, R. Narayanasamy, R. Jeyapaul and C. Loganathan, "Modeling of wrinkling in deep drawing of different grades of annealed commercially pure aluminum sheets when drawn through a conical die using artificial neural network", Materials and Design, vol.30, pp.3193-3205, 
2009.

[47] R. Kazan, M. Frrat and A. E. Tiryaki, "Prediction of springback in wipe-bending process of sheet metal using neural network", Materials and Design, vol.30, pp.418-423, 2009.

[48] H. Aguir,J. L. Alves, M. C. Oliveira, L. F. Menezes, H. BelhadjSalah and R. Hambli, "Identification of anisotropic parameters using the cylindrical cup deep drawing test and the coupled ANN-inverse method", 7th EUROMECH Solid Mechanics Conference, pp. 1-11, 2009.

[49] F. Djavanroodi, A. Pirgholi and E. Derakhshani, "FEM and ANN Analysis in Fine-Blanking Process", Materials and Manufacturing Processes, vol.25, pp.864-872, 2010.

[50] Q. Li, M. Li, Q. Li and Y. Tian, "Optimization Technology of Sheet Metal Deep Drawing with Variable Blank Holder Force", International Conference on Computer, Mechatronics, Control and Electronic Engineering (CMCE), IEEE, pp.495 $-497,2010$.

[51] M. Hanazono, H. Nishimura, H. Harada, Y. Marumo and T. Yamaguchi, "Slide-bending Formation of Metallic Sheet Using Neural Network", International Conference on Control, Automation and Systems, IEEE, pp. 34-37, 2010.

[52] Z. Fu, J. Mo, L. Chen and W. Chen, "Using genetic algorithm-back propagation neural network prediction and finite-element model simulation to optimize the process of multiple-step incremental air-bending forming of sheet metal", Materials and Design, vol. 31 pp.267-277, 2010.

[53] G. Liu and Z. Yi, "Calculation Method study on Spring Back of Automobile Ceiling", Computer Engineering and Technology (ICCET), 2010 2nd International Conference, IEEE, vol. 3 pp.655-658, 2010.

[54] Z. Deng and Y. Zhang, "The precise prediction of Springback Based on GRN", 2010 International Conference on Artificial Intelligence and Computational Intelligence, IEEE, pp.290293, 2010.
[55] P. Gugel and H. Schrödl, Cost Forecast of Sheet Metal Parts using 3D CAD-Models in SME", IEEE, pp.407-408, 2010.

[56] Y. Du, X. Wang and J. Silvanus, "Improved BP network to predict bending angle in the laser bending process for sheet metal", 2010 International Conference on Intelligent System Design and Engineering Application, IEEE computer society, pp.839-843, 2010.

[57] A. Gisario, M. Barletta, C. Conti and S. Guarino, "Springback control in sheet metal bending by laser-assisted bending: Experimental analysis, empirical and neural network modeling", Optics and Lasers in Engineering, vol.49, pp.1372-1383, 2011.

[58] H. Baseri, M. Bakhshi-Jooybari and B. Rahmani, "Modeling of spring-back in V-die bending process by using fuzzy learning back-propagation algorithm", Expert Systems with Applications, vol. 38, pp.8894-8900, 2011.

[59] S. Ren, Y. Lai, G. Wu, J. Gu and Y. Dai, "Intelligent Prediction of Process Parameters for Bending Forming", The Open Mechanical Engineering Journal, vol.5, pp.26-31, 2011.

[60] Y. Zhang, "Optimization of Blank Holder Force Based On CAE and Neural Network", International Conference on Electronic \& Mechanical Engineering and Information Technology, IEEE, pp.2896-2899, 2011.

[61] D. Singh, R. Yousefi and M. Boroushaki, "Identification of Optimum Parameters of Deep Drawing of a Cylindrical Workpiece using Neural Network and Genetic Algorithm", World Academy of Science, Engineering and Technology, vol.78, pp.211-217, 2011.

[62] H. S. Choi, B. M. Kim, K. J. Nam, S. H. Cha and C. G. Kang, Development of hot stamped center pillar using form die with channel type indirect blank holder", International Journal of Automotive Technology, vol. 12, No. 6, pp. 887-894, 2011.

[63] V. Nasrollahi and B. Arezoo, "Prediction of springback in sheet metal components with holes on the bending area, using experiments, finite element and neural networks", Materials and Design, vol. 36, pp.331-336, 2012. 